the Pharmaceutical Industry (AMAPI). It replaces another of the same title published in 1970 (Ed. by E. L. Harris and J. D. Fitzgerald) also based on a symposium organized by the AMAPI. The latter was a very popular book which is now out of print.

Most of the contributors to the 1976 volume are new and it appears to lack the breadth and depth of information included in the former, and does not therefore replace it. Some of the same aspects of clinical trials are covered in more than one chapter, and authors differ in their views on the same subject. There are also occasional, though rare, errors of fact and $a$ few chapters have not been sufficiently well adapted from the spoken word. Inclusion of the discussion from the symposium was a mistake. Despite this, there are many valuable contributions and much good advice for those concerned with clinical trials and clinical research.

Professor Vere raises many issues in his chapter on the ethics of clinical trials. He does not answer them all and makes some suggestions that are clearly controversial. Dr Cuthbert all too briefly outlines the regulations which apply to clinical trials in the U.K. via the Medicines Act. Chapters by Drs James and Smith quite adequately cover the phases for investigation of a new medicine, but one must take issue with Dr Smith over some of the studies he proposes for the period after a new medicine has reached the market (Phase IV). They should surely have been made earlier, and before Phase IV? Some other contributions lack depth and content, and Dr Harcus missed an ideal opportunity to examine more fully the problems of monitoring adverse reactions. Perhaps his chapter was written too early to catch the current concern and spate of publications on this subject. Dr Clifford Hawkins' chapter on the presentation of data is his usual masterpiece on this subject, and a valuable contribution. Some of the best and most useful chapters are amongst the last five, devoted to clinical trials with specific classes of medicines or to specific disease entities.

This volume contains sufficient of value to recommend that it should be read and retained by all those concerned with clinical trials or clinical research. But if you are fortunate enough to have a copy of the 1970 volume, you should keep it, it has not been rendered obsolete by this new book.

\section{Problems of Childhood}

(Series of Articles on the Problems of Childhood published in the B.M.J. in 1976.) Pp. 149, soft cover. British Medical Journal: London, 1976. £2.50 (Inland) $\$ 6.25$ (Abroad US) including postage.

Like most collections of children's short stories there is something in Problems of Childhood to suit the taste of a wide variety of reader. The gifted individual with a relish for facts at any cost to his digestion will no doubt pounce upon $\mathrm{Dr}$ Whaton's article on bottle-feeding. The passivist will savour Mr Sharrard's advice on knock knees, bowlegs, intoeing, etc., 'all sit and wait'-such refreshing rare counsel from an orthopaedic surgeon. But the activist's hunger is also catered for. Dr Downham sweeps away just about every contra-indication to (or controversy against) immunization.

The reactionary (in this case the anti-psyche) perhaps has most to his liking. He will derive immense appetite for $\mathrm{Dr}$ Clayden's classification and explanations for constipation and soiling (how much Hirschsprung disease is being missed by those more head-than tail-orientated?). Breast feeding (Dr Addy) no longer needs Freud to extol its virtues with so much organic science. Even Dr Dodge's slant on recurrent abdominal pain in childhood tends to recoil from the masterful experience of Apley who has shown clearly that the psychosomatic cause is not one of exclusion of organic cause but vice versa. Those looking for plain, nourishing substance will find some excellent pickings: Sarsfield on wheezing children, Meadow on urinary problems, Hatcher on diarrhoea and Harcourt on squint.

Primarily directed at G.P's, a series of articles appearing in the BMJ in 1976 collected together and revised, this book at $£ 2.50$ ( $\$ 6.25$ in USA) is very good value. It should attract a wide readership among medical students and paediatric house officers. Sadly it lacks any semblance of humour or journalistic style.

\section{Recent Advances in Clinical Virology. No. 1}

Edited by A. P. WATERson. Pp. viii +200 , illustrated, hard cover. Churchill Livingstone: Edinburgh, 1977. $£ 9.75$.

This book contains twelve reviews of relevance to the practice of clinical virology. As the editor emphasizes in the preface, clinical virology is not synonymous with medical virology because it includes veterinary as well as medical aspects. However, this volume is mainly devoted to human viral diseases.

There are reviews on the following subjects: herpes encephalitis; subacute sclerosing panencephalitis; Creutzfeldt-Jacob disease; the scrapie agent; rabies vaccination; human papovaviruses; cytomegalovirus vaccine; Lassa fever; Coxsackie virus infections and the heart; acute nonbacterial infectious gastroenteritis; rubella vaccines; measles vaccines.

In an area of medicine which is developing as rapidly as clinical virology, an up-to-date and comprehensive review, written by a specialist in a particular field, is most valuable in the struggle to keep up with recent developments and to evaluate them in terms of previous work. This collection of twelve such reviews is therefore a worthwhile purchase for all with an interest in virus disease of the human or animals. In addition, as one may gather from the list of titles, a substantial amount of the book is concerned with virus diseases of the central nervous system. This, together with the chapters on virus vaccines, should result in the book being welcomed by neurologists, paediatricians and workers in other clinical specialities.

Perhaps in the next volume of this series there will be a larger contribution from workers in the veterinary field, and if it reaches the high standard of volume 1 it is eagerly awaited by this reviewer.

\section{A Short Textbook of General Practice (3rd edition)}

By Denis Craddock. Pp. xvi +741 , hard cover, H. K. Lewis: London, 1976. $£ 12.00$.

It is nearly 25 years since the first edition of this book appeared. At that time general practice was in the doldrums and the idea that there might be a need for a textbook about it must have seemed strange to many. Although a College of General Practitioners had been formed in Britain, no examination was needed for entry. In this, the third edition, Denis Craddock - now the Honorary Librarian of the RCGP -has enlarged his text with the expressed aim of covering the syllabus for the Membership examination for that College. Although part of the text, particularly that relevant to administration within the NHS, is not directly pertinent to those who practise in other countries, the rest of the book certainly is. Indeed, many may well enjoy reading some facts about the British National Health Service.

The introductory five pages describe what general practice is all about, not only in Britain, and this section could well be read with advantage by those in hospital practice. There follow six short chapters on practice organization and then seven on normal development and behaviour from conception to the grave, with the last chapter in this section 